\title{
Editorials
}

\section{Gender incongruence in children, adolescents, and adults}

More individuals are requesting medical assistance for gender uncertainty or dysphoria and provision of adult NHS gender identity services (GIS) is changing. 'Despite minimal medical input to polarised debates, several issues are potentially concerning: reports of poor care; rapid rises in referrals of children and young people to GIS; ${ }^{2}$ public conflation of biological sex with socially influenced gender roles; and extensive uncertainty in the evidence base to guide practice. ${ }^{3}$

Medical practice should happen within robust human rights frameworks where individual patients always have their concerns heard. Generalists, with expertise in wholeperson care, handling uncertainty and complexity, have a key role when consulted by identity-questioning and transgender individuals for routine care, gender identity concerns, treatments recommended by private or NHS services, or for referral. Presentations with prior emotional trauma, co-existing mental or neurodevelopmental issues, or 'bridging hormones' requests may make primary care professionals uneasy. Without a considered approach to practice, high-quality evidence and guidance, a policy of active 'affirmation' and 'treat or refer' may lead to more people receiving medical interventions with uncertain outcomes.

\section{CHANGING THE LANDSCAPE}

The characteristics of those seeking help are changing. In the past thesewere predominantly for male to female medical transition. Contemporarily, many younger people identify with a range of gender types (such as, trans, fluid, non-binary, gender-queer) and there is greater difficulty distinguishing overlaps with imaginative processes. The majority presenting before puberty desist. Some, but not all, seek interventions with uncertain longterm outcomes. There is growing demand for GPs to prescribe cross-sex hormones before specialist assessments but GMC and BMA positions differ. 4.5 More definitive knowledge is needed about: the causes of rapid increased referrals, especially girls and young females; the outcomes of interventions or 'wait and see' policies in this new demographic; and how to practice and organise services, especially anticipating long-term health implications.

The planned recommissioning of adult GIS in England provides an opportunity to develop best practice through integrated programmes of training, research, and service redesign. Multidisciplinary approaches used within child and adolescent services might ensure that adults now being referred also receive whole-person comprehensive support.

\section{UNDERSTANDING RISE IN REFERRALS}

No robust analysis explains why referrals have risen so fast. While some individuals feel able to disclose earlier in a less stigmatised context, it is possible that gender identity

\section{Box 1. Medical uncertainties and our response to gender dysphoria}

\begin{tabular}{|c|c|}
\hline Medical uncertainties & Response \\
\hline $\begin{array}{l}\text { What are the causes of } \\
\text { gender dysphoria? }\end{array}$ & $\begin{array}{l}\text { The causes of feeling uncomfortable with one's biological sex are unclear } \\
\text { but likely to be multifactorial and include society's expectations of gender } \\
\text { roles. }\end{array}$ \\
\hline $\begin{array}{l}\text { Is there a biological basis for } \\
\text { the concept of 'being born in } \\
\text { the wrong body'? }\end{array}$ & $\begin{array}{l}\text { Humans are sexually dimorphic, with rare intersex conditions being } \\
\text { anomalous developments of dimorphic sexual classes. It is not possible to } \\
\text { change biological sex. There is no agreed scientific basis for someone } \\
\text { having the mind of someone from the opposite sex or being born in the } \\
\text { wrong body. }\end{array}$ \\
\hline $\begin{array}{l}\text { How should a child or young } \\
\text { person questioning their sexual } \\
\text { or gender identity be supported? }\end{array}$ & $\begin{array}{l}\text { Questioning is a normal part of growing up, as is discomfort during } \\
\text { puberty. Young people should be encouraged to talk about their worries as } \\
\text { they may not have other people they can trust outside of peer groups. }\end{array}$ \\
\hline $\begin{array}{l}\text { What do shared decision } \\
\text { making look like in the } \\
\text { absence of evidence? }\end{array}$ & $\begin{array}{l}\text { Generalists should feel confident and supported to explore the potential } \\
\text { links between gender questioning, emotions and cognitions, and the } \\
\text { cultural context. Differences in views are likely to occur and provide the } \\
\text { basis for each party to shift position. }\end{array}$ \\
\hline $\begin{array}{l}\text { How should we advise patients } \\
\text { about the outcomes of } \\
\text { medical treatments given the } \\
\text { paucity of evidence? }\end{array}$ & $\begin{array}{l}\text { Medical practitioners should be open and clear that, while satisfaction has } \\
\text { been high for previous cohorts, we know little about the impact on physical } \\
\text { (for example, fertility), emotional, and social (future intimate relationships) } \\
\text { outcomes for the current younger and mainly female group presenting. }\end{array}$ \\
\hline
\end{tabular}

uncertainty and dysphoria may be generated or exacerbated by societal and psychological factors, particularly during puberty. A study of concerned US parents reported their transidentifying children had previously identified as gay, had mental health or neurodevelopmental problems, recent onset dysphoria, or were in friendship groups with other trans-identifying individuals. ${ }^{6}$ The paper drew intense criticism despite acknowledging limitations including distinguishing cause and effect. Likely, the rise is multifactorial: $35 \%$ of those seen in the Tavistock service have autism traits: ${ }^{1}$ some females may favour traditional male roles; current female stereotypes and appearances may be rejected; some young females who are attracted to other females may initially believe they are transmen, but later identify as lesbians. While sexual orientation and gender identity are distinct, such confusion is now not uncommon.

\section{INTERVENTION OUTCOMES}

While a low-quality observational study of mainly older male-to-female full transitions has shown high levels of satisfaction, ${ }^{7}$ there are no robust contemporary cohort studies of younger female-to-male outcomes, ${ }^{1}$ nor of supportive, non-invasive interventions. Adolescents, who previously may have come to terms naturally with the emotional difficulties of pubescent bodies or with emergent homosexuality, may consider themselves to be 'trans' and be offered puberty-blocking drugs prior to psychoactive steroid hormones and irreversible surgery. We lack information whether these improve outcome, including reproductive consequences. Improved mental wellbeing is the main rationale for intervention though one study shows high rates of suicide after surgery. ${ }^{8}$ This could be due to ineffective treatment, ongoing prejudice, or co-existent mental illness. Rates of persistence, benefits and complications, regret, and detransition, are unclear. Practitioners have been sued for not providing sufficient assessment or information.?

\section{PATHWAYS TO MEDICAL INTERVENTIONS}

Gender-questioning individuals need protection from discrimination, high quality services, and clear information. Professionals should be able to refer to bodies of evidence and guidelines, but there is no UK guidance designed for generalists. Some international guidelines advocate 'affirming' an individual's expressed gender. The 2017 UKMemorandum 
of Understanding on Conversion Therapy, ${ }_{10}^{10}$ signed by the RCGP (but not the Royal College of Psychiatrists), rejects formal 'conversion therapy', but also states that actions which contribute to a change to gender identity could be seen as 'covert' conversion. So practitioners might infer they should not explore wider issues or discuss harms of interventions. This would be counter to consultation models which encourage evidence sharing and leave room for differing views.

Paradoxically, calls for medical intervention refer to mental distress and suicide risk, while psychiatric assessment is often rejected. This is worrying as there are no objective tests for gender dysphoria, which has no agreed physical basis and is assessed by interview. It may be effected by social and cultural context and has the potential to change over time. In contrast to previous debates about depathologisation of sexual orientation, which led to demedicalisation, the opposite may occur here; while helping some, interventions can result in ongoing side effects and medical dependency. Medical intervention may, in effect, become another form of 'conversion,' whereby some children who would otherwise have grown up gay or lesbian receive "gender affirming' cross-sex treatments instead.

Much patient information does not fully express the known uncertainties of interventions. Many healthcare organisations and schools have been educated by charities and non-NHS groups using inaccurate information, including exaggerated risks of suicide. ${ }^{11}$ NHS material contains concepts that biological sex is assigned at birth (rather than observedl and that surgery can change sex. The wide range of treatment experiences and outcomes including desistance need to be included.

For children and young people, an individualised age-and-developmental-stage approach is required. The facts in each case will influence consultation style, for example, where does the child live, and with whom? Who are the key carers? Is the child in education or employment? What are prior family values and current concerns? Are there conflicts or safety issues? Practitioners can draw on a variety of familiar consultation skills, such as seeing the child alone and together with family or trusted friends, gradually gaining insight, allowing the 'test of time'. In general, GPs will want to include parents and/or guardians in consultations, aiming for all parties to find common ground in their legal obligations under the Children's Act 1989 using the best interests test.

A number of consultation approaches may be considered: use clear, respectful language and the patient's preferred form of address; take a non-judgemental person-centred approach; reflect on personal biases; allow a few appointments to explore issues and the time frame of gender-related distress, whether the individual is questioning or has firm beliefs, and how feelings of gender relate to sexuality; assess associated mental health issues such as self harm, anxiety, or body dysmorphia, as well as autism traits; enquire about relationships with family, friends, intimate partners, and online groups, and how these relate to the patient's views and wishes; remember sex is biological and fixed while gender relates to social roles; allow respectful space for differing views; share understanding of the uncertainties of long-term treatment; and share literature from a variety of sources to discuss at future meetings (Box 1).

\section{IMMEDIATE ACTION AND RESEARCH}

Immediate action could include: examination of NHS literature on evidence and uncertainty; creation of coherent guidance for practitioners not specialising in gender identity; a national survey of doctors to understand views and concerns, and development of training to ensure practitioners are competent and understand the evidence.

Well-funded, independent, long-term research is required to ensure doctors meet their ethical duties to 'first do no harm' and fulfil good medical practice. Research could include: exploration of the interplays between gender dysphoria, mental health problems, autism spectrum disorders, sexual orientation, autogynephilia, and unpalatable societal gender roles; and exploration of the different assessment and diagnosis models; trials of different strategies, including waitand-see versus intervention for young people, puberty-blocking, hormonal, and surgical treatments.

National reconfiguration of services is a chance to integrate research, service redesign, and training, with the creation of ongoing cohorts to monitor immediate and longer-term outcomes for all those referred and receiving different interventions.

\section{Susan Bewley,}

Professor Emeritus of Obstetrics and Women's Health, Department of Women and Children's Health, St Thomas' Hospital, London.

\section{Damian Clifford,}

Consultant Psychiatrist, Cornwall Partnership NHS Foundation Trust, Bodmin, Cornwall.

\section{Margaret McCartney,}

GP, Fulton Street Medical Practice, Glasgow.

\section{Richard Byng,}

GP and Academic, Community and Primary Care Research Group, Faculty of Medicine and Dentistry, University of Plymouth, Plymouth.

\section{ADDRESS FOR CORRESPONDENCE}

\section{Susan Bewley}

Department of Women and Children's Health, Kings College London, 10th Floor North Wing, St Thomas Hospital, Westminster Bridge Road, London SE1 7EH UK.

Email: susan.bewleyßkcl.ac.uk

\section{Provenance}

Freely submitted; externally peer reviewed.

\section{Competing interests}

The authors have declared no competing interests.

\section{DOI: https://doi.org/10.3399/bjgp19X701909}

\section{REFERENCES}

. Butler G, De Graaf N, Wren B, Carmichael P. Assessment and support of children and adolescents with gender dysphoria. Arch Dis Child 2018; 103(7): 631-636.

2. The Tavistock and Portman NHS Foundation Trust. GIDS referrals increase in 2017/18. 2018 https://tavistockandportman.nhs.uk/about-us/ news/stories/gids-referrals-increase-201718/ (accessed 8 Mar 2018)

3. Byng R, Bewley S, Clifford D, McCartney M. Redesigning gender identity services: an opportunity to generate evidence. BMJ 2018; 363: $k 4490$

4. General Medical Council. Trans healthcare. https://uww.gmc-uk.org/ethical-guidance/ ethical-hub/trans-healthcare---advice-basedon-gmc-guidance\#prescribing laccessed Mar March 2018).

5. British Medical Association. Gender incongruence in primary care. 2018. https:// unw.bma.org.uk/advice/employment/ gp-practices/service-provision/prescribing/ gender-incongruence-in-primary-care (accessed 8 Mar 2019).

6. Littman L. Rapid-onset gender dysphoria in adolescents and young adults: a study of parental reports. PLoS One 2018; 13(8): e0202330.

7. Mural MH, Elamin MB, Garcia MZ, et al. Hormonal therapy and sex reassignment: a systematic review and meta-analysis of quality of life and psychosocial outcomes. Clin Endocrinol (Oxf) 2010; 72(2): 214-231.

8. Dhejne $\mathrm{C}$, Lichtenstein $\mathrm{P}$, Boman M, et al. Long-term follow-up of transsexual persons undergoing sex reassignment surgery: cohort study in Sweden. PLoS One 2011; 6(2): e16885.

9. Pollock N. 'I wanted to take my body off': detransitioned. 2018. Jun: https://mmw. theatlantic.com/video/index/562988/ detransitioned-film/ (accessed 8 Mar 2018).

10. UK Council for Psychotherapy.Memorandum of Understanding on Conversion Therapy in the UK. https://www.bpc.org.uk/sites/ psychoanalytic-council.org/files/MoU2 FINAL_0. pdf (accessed 8 Mar 2019).

11. Hutchinson K. Kate Hutchinson: Wrexham to Euston - my journey to meet the General Medical Council. 2017. https://unw. allabouttrans.org.uk/kate-hutchinson-wrexhameuston-journey-meet-general-medical-council/ laccessed 8 Mar 2018). 